\title{
Help Others and Yourself Eventually: Exploring the Relationship between Help-Giving and Employee Creativity under the Model of Perspective Taking
}

\section{Si Li" and Shudi Liao ${ }^{2 *}$ \\ ${ }^{1}$ School of Management, Huazhong University of Science and Technology, Wuhan, China, ${ }^{2}$ School of Business, Hubei University, Wuhan, China}

Although a plethora of studies have examined the antecedents of creativity, empirical studies exploring the role of individual behaviors in relation to creativity are relatively scarce. Drawing on the model of perspective taking, this study examines the relationship between help-giving during creative problem solving process and employee creativity. Specifically, we test perspective taking as an explanatory mechanism and propose organization-based self-esteem as the moderator. In a sample collected from a field survey of 247 supervisor-subordinate dyads from 2 large organizations in China at 3 time points, we find that help-giving during creative problem solving process positively related with perspective taking; perspective taking positively related with employees' creativity; employees' organization-based self-esteem strengthened the link between perspective taking and creativity; besides, there existed a moderated mediation effect. We conclude this paper with discussions on the implications for theory, research, and practice.

Keywords: creativity, help-giving, organization-based self-esteem (OBSE), organizational citizenship behavior (OCB), perspective taking

\section{INTRODUCTION}

Past decades have witnessed the burgeoning research interest in identifying drivers that might facilitate employees' engagement in creativity, which is defined as the generation of novel and useful ideas (Amabile, 1983; Shalley, 1991). Though studies exploring the antecedents of creativity have accumulated rapidly, most of them are focused on the individual factors like cognition, affect and motivation, and contextual predictors (Shalley et al., 2004). It is surprising, however, that scant literature has considered individual behaviors (e.g., De Stobbeleir et al., 2011; Černe et al., 2014, for exception). As interpersonal process initiated by individuals have a great influence on individuallevel creativity (Perry-Smith and Shalley, 2003; Shalley et al., 2004; George, 2007), and in response to Zhou and Hoever's (2014) call for incorporating new perspectives, this study goes beyond usual practice and discusses individual behavior as predictors of creativity.

Help-giving is one of such a behavior, depicting individuals" "willing devotion of time and attention to assist with the work of others" (Hargadon and Bechky, 2006, p. 489). During organizations' progress to achieve creativity, work starts to get more and more complex and interdependent, which makes team or group structures quite pertinent and as a result, team or 
group structures are becoming more and more prevalent (Stevens and Campion, 1994; Cohen and Bailey, 1997). In this background, to attain group effectiveness, interpersonal facilitation becomes indispensable, of which helping behaviors is one of the most salient forms that could cultivate interpersonal coordination and integration (Van Scotter and Motowidlo, 1996). For example, Hargadon and Bechky (2006) found that employees within organizations implicitly assumed that it is inevitable to ask for help to implement organizational knowledge. Moreover, Perlow (1999) discovered that within the R\&D group, individuals have to get help from others to accomplish their work. To sum up, both the empirical and theoretical evidence suggested that helping behaviors are essential and indispensable within organizational progress.

Nonetheless, recent work by Mueller and Kamdar (2011) suggested a negative link between help-giving behavior and creativity. According to their study, help-giving is a "curse" for individual creativity. One of their major arguments is that individuals' personal resources are finite and limited (Hobfoll, 1989). While, the act of help-giving can diminish the amount of time or energy that could have been devoted to his or her own tasks (Bergeron, 2007). Consistent with this perspective, a wide array of research indicate that helping behaviors positively relate to citizenship fatigue (Bolino et al., 2015), role overload, job stress, work-family conflict (Bolino and Turnley, 2005), and diminish task performance (Bergeron, 2007; Barnes et al., 2008). To extend this logic further, it is easy to assume that help-giving might be harmful for individual creativity as well.

A somewhat thorough perusal of the help-giving literature, however, cast doubt on the assumed negative relationship between help-giving and creativity. Katz and Kahn (1978), for instance, once posited that OCB itself is a spontaneous, and "innovative" behavior. Aligning with this argument, Kesen (2016) found that four dimensions of OCB (conscientiousness, helping, civic virtue and sportsmanship) all positively relate to creativity. The mixed results posit an intriguing question about the actual relationship between help-giving and creativity. Accordingly, instead of denying the existing evidence suggesting its detrimental effects, the present paper aims to explore the potential benefits of help-giving by examining how and when help-giving would benefit employee's creativity.

According to the model of perspective taking, job-related factors and individual factors both could predict individuals' perspective taking, thus further results in cooperation-oriented contextual performance (Parker and Axtell, 2001). Drawing upon this model, we propose that help-giving during creative problem solving process might evoke employees' perspective taking, thus further facilitates their creativity, and this effect is contingent on employee's organization-based self-esteem (OBSE). Unlike cooperative contextual performance, creativity has always been viewed as a process full of uncertainties and high rates of failure (Simonton, 1984; Metcalfe and Wiebe, 1987; Fleming, 2001). Thus, individual characteristics like self-esteem could play an important role in explaining individuals' different reactions to the same situations (Brockner, 1988), and here we adopt individuals' OBSE as the moderator. In doing so, we make several contributions. Firstly, our study complements the current creativity literature, as previous research concerning predictors of creativity predominantly focus on individual difference and psychological process. In response to the call for more attention beyond the previous theoretical perspective (Zhou and Hoever, 2014), the present study finds out that help-giving, as a prosocial behavior, could also contribute to individuals' creativity. Secondly, based on the model of perspective taking, we disentangle the indirect effect of perspective taking on the relationship between help-giving behaviors and creativity. As extant research concerning the link between helping behaviors and creativity shows inconsistent results, our study argues that workplace interaction such as help-giving could evoke individual' perspective taking, which provides a novel insight into the mixed link. Finally, our study unearths that employees' OBSE moderates the link between perspective taking and creativity. While prior research suggests that OBSE directly impacts employee creativity (Chen and Aryee, 2007), our study further points out that it also enhances the positive relationship between perspective taking and creativity. Therefore, we demonstrate the importance to theory and practice of considering self-concept not only as mediators to creativity but also as moderators.

\section{Theories and Hypotheses}

According to the model of perspective taking, Parker and Axtell (2001) mainly adopt two approaches to conceptualize perspective taking. One of which takes on the dispositional approach and considers it as a relatively stable trait depicting individuals' ability to perceive others' feelings; the other considers it in a situational approach which suggests that individuals' perspective taking responds to external factors. Align with Parker and Axtell (2001) as well as our research intention, we are primarily concerned with the situational approach in the present paper. Specifically, perspective taking is a cognitive-affective experience that varies from situations, which suggests that it not only comprises cognitive process, which is referred to as "intellectual empathy," but also includes affective component, which is referred to as "empathic emotions" (Duan and Hill, 1996). What's more, based on Duan and Hill's (1996), the model posits that the cognitive process could result in the affective response of empathy along with positive attributions toward the target. In addition, Parker and Axtell (2001) delineate that job-related attributes like interaction with targets and job autonomy, and individual factors like experience of targets' job, flexible role orientation and integrated understanding, all could predict perspective taking. Besides, job-related attributes could also influence perspective taking indirectly via individual factors (flexible role orientation and integrated understanding).

Moreover, the model suggests that individuals' perspective taking could promote contextual performance, especially the cooperation-oriented ones. Notebly, a series of studies have testified and supported the positive link between perspective taking and helping behaviors (c.f., Underwood and Moore, 1982; Oswald, 1996; Batson, 1997; Maner et al., 2002). Nonetheless, with empirical evidence suggesting that there are reliable associations between perspective taking and helping behavior (Underwood and Moore, 1982; Maner et al., 2002), we boldly assume that there might exist a reciprocal process, as indicated 
by Parker and Axtell (2001) as well. And that is, individuals' help-giving behaviors could also promote perspective taking, especially during the creative problem solving process.

In the team contexts, help-giving behaviors during creative problem solving process underlies that individuals give help to others by gathering and utilizing information to generate creative outcomes (Mueller and Kamdar, 2011). Specifically, the team contexts indicate the interdependence of the working procedure and their common team goal. In this setting, based upon the model of perspective taking, we propose that individuals' help-giving during creative problem solving process could evoke their perspective taking behaviors. On the one hand, as part of organizational citizenship behavior (OCB), giving help inevitably initiates social interactions with others, which enables individuals to expose to alternative ways of thinking of the targets that they are giving help, thus further predict perspective taking directly; on the other hand, this kind of social interaction could facilitate integrated understanding and flexible role orientation, thus enhances perspective taking indirectly.

For one thing, help-giving could facilitate integrated understanding. In order to better help those who seek help from them, individuals have to think in their shoes, which could help broaden their perspective about the work context, like how their work relates to each other, and help them have a big picture of the whole woke design.

For another, help-giving behaviors during creative problem solving process could lead to their flexible role orientation in two ways. Flexible role orientation refers to individuals' emergent and flexible view of their role (Parker et al., 1997). Firstly, one of the salient characteristics of current organizations is the clear-cut division of labor, which means that employees are being assigned with different work tasks and responsibilities, even in the team contexts (Durkheim, 2014). As a result, employees are fully aware of their working boundaries, that is, what is their job and what is not. As help-giving behaviors are out role performance, which means that individuals who exhibit that should exert extra cognitive and emotional effort. Individuals who frequently conduct these behaviors, the boundaries of their job and role expectation could be expanded to include both the self and organizational role (Perlow, 1998; Tepper et al., 2001; Bolino and Turnley, 2005). Accordingly, an emergent and flexible view of their roles might emerge, which means that they will have a broader perspective and a wider acceptance of their job responsibilities. Secondly, help-giving during creative problem solving process usually involves making decisions about different creative alternatives. According to Davis and Wacker (1987), participation in decisions about change make individuals more likely to develop ownership for that change. This ownership for change during the creative problem solving process usually involves accountability for the creative outcomes, rather than merely for its own working outcomes, which refers to flexible role orientation as well. Altogether, individuals are more likely to feel concerned about and accountable for others' work and their problems and put effort to resolve them, one of the manifestations is perspective taking.

In addition, help-giving behavior might also lead to individuals' experience of others' job. Specifically, in certain situations, in order to help others to accomplish their work, individuals need to help others to complete their job or even doing their job for them, which inevitably involves experience of their job, this shared experience of the same events with others creates empathy and perspective taking (Batson et al., 1996).

To sum up, individuals' help-giving during the creative process could help them to experience others' job, have a flexible role orientation and an integrated understanding of the workplace. According to the model of perspective taking, these help-giving behaviors could lead to their perspective taking. Thus. We propose that:

Hypothesis 1: Help-giving during creative problem solving positively relates to perspective taking.

Meanwhile, the model of perspective taking articulates that perspective taking behaviors could enhance interpersonal facilitation, one of which is cooperative contextual performance that supports the work context. Here, we extend this model and suggest that individuals' perspective taking provoked by helpgiving during creative process could also lead to creativity, which is one of the 10 dimensions of overall job performance ( $\mathrm{Ng}$ and Feldman, 2008), based on the following two reasons.

As noted before, creativity comprises two orthogonal dimensions: novelty and usefulness (Amabile, 1996). The novelty dimension denotes something new and original, and the usefulness dimension illustrates that creativity also entails utility which suggests that creative ideas need to be useful and valuable to others. While, perspective taking behaviors during the creative process could somehow fulfill both dimensions.

On the one hand, when employees take others' perspectives selectively, they are spontaneously exposed to various opinions and diverse viewpoints, which could be seen as a prerequisite for creativity to happen since it provides the basic resource, i.e., information, especially during the creative process, peers' viewpoints are not only relevant but also novel, original, and unique for employees to develop creative ideas. Evidence has suggested that perspective taking behavior can directly contribute to creativity by exposing focal ones to new ideas (Galinsky et al., 2008).

On the other hand, the model of perspective taking demonstrates two fundamental manifestations. One is empathy with the targets, which means individuals will be more likely to identify, understand, and feel concerned about the targets' experience; the other is positive attributions about the targets, which indicates that attributions about target's behavior and outcomes are more "self-like" and positive. Both of these two, according to Davis et al. (1996), provide a favored status for the target, whose perspectives have been taken. Besides, Batson and Powell (2003) suggest that perspective taking would inspire altruism. What's more, Mohrman et al. (2001) suggest that perspective taking between relevant communities, such as researchers and practitioners, could make the associated outcomes like organizational research more useful. To extend this logic further, perspective taking of others during creative process would increase the usefulness of those creative ideas. Taken together, perspective taking could promote individuals 
who take others' perspectives to develop ideas that are useful to others.

To sum up, organizational creativity entails both novelty and usefulness (Guilford, 1967). For one thing, the exposure to others' opinions during the creative process could imperceptibly enhance the novelty of individuals own creative idea. For another, the inclusion of others in one's self-concept could also facilitate the usefulness of the creative ideas. Thus, we propose that:

Hypothesis 2: Perspective taking positively relates to creativity.

Hence, we further propose that help-giving behavior during creative problem solving process could contribute to employees' creativity via the indirect effect of perspective taking. Specifically:

Hypothesis 3: Help-giving during creative problem solving process positively relates with creativity via the indirect effect of perspective taking.

According to Brockner (1988), individual difference like self-esteem plays a vital part in individuals' reactions to external environment. As a situational self-esteem, OBSE refers to the extent to which individuals believe themselves to be worthy, capable and significant as an organization member (Pierce et al., 1989). Notebly, OBSE reflects individual's self-esteem within organizational contexts and it is construed by individuals' past direct and personal experience, like task accomplishments and failures (Korman, 1970, 1976; Brockner, 1988). Additionally, Pierce et al. (1989) also indicate that OBSE is better than global self-esteem in predicting organizational-related behaviors and attitudes. Specifically, individuals develop attitudes and engage in behaviors that align with their organizational roles to maintain or enhance their self-esteem. Meanwhile, research has found that OBSE is positively related to a wide range of outcomes, such as job satisfaction, intrinsic motivation, citizenship behaviors and organization-related attitudes and behaviors, etc. (Pierce et al., 1989; Pierce and Gardner, 2004).

Here, we argue that individuals' OBSE could strengthen the relationship between employees' perspective taking and their creativity for the following reasoning. According to Korman's (1970) self-consistency theory, individuals will engage in activities that are consistent with their self-cognition and self-images in job situations. Specifically, individuals with positive images and cognition of themselves would engage in behaviors that enhance that positive image and cognition; whereas, individuals with negative image or cognition would engage in behaviors that are in accordance with the negative image or cognition. To extend this logic further, unlike cooperation-oriented contextual performance, scholars have suggested that the creative process are often accompanied by uncertainties and unpredictability as well as high rates of failure (Simonton, 1984; Metcalfe and Wiebe, 1987; Fleming, 2001). Thus, individuals with low OBSE might be uncertain and lack of confidence of their capability to overcome barriers and pursue creative outcomes, thus avoid the creative endeavor. In contrast, as construed by their past experience of success and failure, individuals with high OBSE usually view themselves as valuable, competent and meaningful existence within the organizations, thus are more likely to conduct behaviors that could exhibit their competence and boost their organizational contribution. In the context of the creative team process, thinking out a creative idea could definitely demonstrate one's personal competence and elevate one's standing within teams, thus individuals with high OBSE might persist on the pursuit of creativity regardless of the uncertainties and possible failures. Research has echoed this argument by demonstrating that even accompanied by creative self-efficacy and creativity skills, the lack of basic skill or general efficacy could also prevent the occurrence of creativity (Amabile, 1983, 1988; Tierney and Farmer, 2002). When individuals lack confidence of their basic capability to conduct job within teams, even in the presence of strong creativity resources, it is still hard for them to utilize those creativity resources and generate creative outcomes. Hence:

Hypothesis 4: Organization-based self-esteem moderates the relationship between perspective taking and creativity such that the positive relationship between perspective taking and creativity strengthens when OBSE is higher.

As was stated above, individuals' OBSE moderates the link between perspective taking and creativity, it is also possible that individuals' OBSE can influence the strength of the indirect effect of help-giving behaviors during creative problem solving process and creativity. Hence, we propose that:

Hypothesis 5: Organization-based self-esteem moderates the positive indirect effect of help-giving during creative problem solving and creativity (through perspective taking). Specifically, higher levels of OBSE strengthens the extent to which perspective taking mediates the indirect effect of help-giving during creative problem solving and creativity.

Figure 1 summarizes our proposed theoretical model.

\section{MATERIALS AND METHODS}

\section{Sample and Procedure}

We collected data from two large logistics enterprises distributed in two cities, including Guangzhou, and Shanghai, in China within 3 months. The research departments of both the two companies mainly comprised project teams who are responsible for the planning of logistics routes and coping with all kinds of emergency, which entails rapid response capabilities and creative problem solving capabilities. To avoid common method bias, we adopt a three-wave study, and the interval between each investigation was 2 months. Employees completed their questionnaires in the first and second phases, then their corresponding supervisors finished their questionnaires in the third phase. All the employees and supervisors completed their questionnaires on their own without discussion. Then we collected all the on-site questionnaires immediately. The operations of all the investigations were the same. The surveys were originally constructed in English and then translated into Chinese using the back-translation procedure for the assurance of equivalence of the measures (Brislin, 1986). 




FIGURE 1| Theoretical framework. Notes: Help-giving behavior: Time 1 by subordinate; Perspective taking: Time 2 by subordinate; OBSE: Time 2 by subordinate; Creativity: Time 3 by supervisor.

During the first investigation, we distributed 450 dyadic questionnaires and retrieved 327 dyadic questionnaires, and the response rate was $72.67 \%$; the second investigation then targeted at these 327 dyads and retrieved 283 dyadic complete questionnaires, and the response rate was $86.54 \%$; the third investigation then targeted at these 283 dyads, and we collected 247 valid dyadic questionnaires, and the response rate was $87.28 \%$. Among the supervisors, male supervisors account $46.4 \%$, the average age is 38.35 , the average position tenure is 7.2 years, $67.9 \%$ of them have bachelor's degree and higher qualifications. In the samples of employees, $42.9 \%$ are male employees, the average age is $31.88,65.2 \%$ of them have bachelor's degree and higher qualifications, average position tenure is 5.4 years, average organization tenure is 7.42 years.

\section{Ethics Statement}

Before starting the data collection, we consulted our university's ethics committee and was approved to conduct this research. According to our research design, the study did not violate any legal regulations or common ethical guidelines. To further ensure the ethical innocuousness of the study, before distributing questionnaires, we again introduced our research goal, and the research plan concerning each participants to them, and asked for their permission and consent to participate in the investigations, and emphasized that as soon as they feel inappropriate, they could quit and their incomplete data would be deleted and not assessed.

\section{Measures}

Unless otherwise indicated, all items used a 7-point scale, ranging from "strongly disagree"(1) to "strongly agree"(7).

\section{Help-Giving Behavior (Time 1)}

We adapted a six-item scale from Mueller and Kamdar (2011) which focuses on specific help-giving behaviors targeting creative problem solving process. Employees self-report their help-giving behaviors at the first stage. Sample items include "I go out of my way to help coworkers refine their creative ideas"(Cronbach's alpha $=0.923$ ).

\section{Perspective Taking (Time 2)}

Employees indicated their extent to take others' views into consideration with a four-item scale developed by Davis et al.
(1996). Sample item is "On the job, I frequently try to take other people's perspectives" (Cronbach's alpha $=0.946$ ).

\section{Organization-Based Self-esteem (Time 2)}

Employees reported their OBSE using a 10-item scale developed by Pierce et al. (1989). Sample items include "I can make a difference." (Cronbach's alpha $=0.911)$.

\section{Creativity (Time 3)}

Supervisors rated employee's creativity using 13-items scale developed by Zhou and George (2001). Sample items include "Comes up with new and practical ideas to improve performance.”(Cronbach's alpha $=0.973$ ).

\section{Control Variables}

Employees' demographic variables have been controlled, such as age, gender, educational levels, and organization tenure, because of their potential effects on creativity (Mumford and Gustafson, 1988; Mumford, 2003; Shin and Zhou, 2003); Moreover, we also controlled the organizational membership to remove any possible biases by adopting dummy-coded variables.

\section{RESULTS}

We then conducted confirmatory factor analyses with maximum likelihood estimation to examine the distinctness of the variables.

\section{Confirmatory Factor Analysis Results}

As indicated in Table 1, confirmatory factor analyses indicated that the hypothesized factor structure fitted these data better than the alternative models examined (e.g., $\chi^{2}(481)=1336.548$, $p<0.001$, RMSEA $=0.085$, CFI $=0.902$, IFI $=0.903$, $\left.\chi^{2} / d f=2.779\right)$. Moreover, we conducted a more rigorous test to assess the discriminant validity (Hair et al., 2010). By comparing the average variance extracted values for any of the two constructs with the square of the correlation estimate between these two constructs, we could assess the discriminant validity. And, we calculated the AVES (average variance extracted) of each construct and they are all above 0.5, and are greater than the squared correlation estimate. Moreover, the AVE values of any 
TABLE 1 | Summary of model fit indexes.

\begin{tabular}{|c|c|c|c|c|c|c|}
\hline Factor structure & $x^{2}$ & $d f$ & $x^{2} / d f$ & IFI & CFI & RMSEA \\
\hline One-factor model: (Help-giving + Perspective taking + OBSE + Creativity) & 4438.252 & 487 & 9.113 & 0.550 & 0.548 & 0.182 \\
\hline Two-factor model: (Help-giving + Perspective taking + OBSE), Creativity & 2922.524 & 486 & 6.013 & 0.722 & 0.721 & 6.013 \\
\hline Three-factor model: Help-giving, (Perspective taking + OBSE), Creativity & 2045.643 & 484 & 4.227 & 0.822 & 0.821 & 4.227 \\
\hline Four-factor model: Help-giving, Perspective taking, OBSE, Creativity & 1336.548 & 481 & 2.779 & 0.903 & 0.902 & 0.085 \\
\hline
\end{tabular}

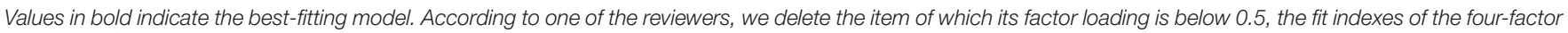
model are $x^{2}=1224.136, d f=451, x^{2} / d f=2.714, I F I=0.910, C F I=0.910, R M S E A=0.084$.

two constructs are also greater than their squared correlation estimate. In addition, we also calculated the composite reliability of each construct, which is above 0.9. See Table 2.

\section{Descriptive Statistics and Correlations}

Table 3 shows the descriptive statistics, intercorrelations, and reliabilities for the study variables. Organization tenure negatively relates with individuals' help-giving behaviors ( $\beta=-0.197, p<0.01)$, but positively relates with individuals' creativity $(\beta=0.213, p<0.01)$. Help-giving behavior positively relates with perspective taking $(\beta=0.309, p<0.01)$, perspective taking positively relates with $\mathrm{OBSE}(\beta=0.513, p<0.01)$, and creativity $(\beta=0.163, p<0.01)$. And, OBSE positively relates with individuals' creativity $(\beta=0.119, p<0.05)$.

\section{Results of Tests of the Hypotheses}

Since undertaking mediation analysis, Baron and Kenny's (1986) approach is no longer considered appropriate, to further confirm the hypotheses and test the moderated mediation effect, we adopt Hayes's PROCESS Macro for SPSS to measure the indirect effects for mediation and moderated mediation (Hayes, 2013), which is also recommended by Edwards and Lambert (2007). The results are reported in Table 4. By using 5,000 bootstrap estimates for the construction of $95 \%$ bias-corrected CIs, the results demonstrated that the direct effect of help-giving behavior on employees' creativity was not significant, as the confidence intervals (CI) included zero (95\% CI $[-0.119,0.142])$. While, help-giving behavior was significantly positively related to perspective taking ( $\beta=0.295, p<0.001,95 \%$ CI [0.193,0.396]), and perspective taking was significantly and positively related to creativity as well $(\beta=0.205, p<0.05,95 \%$ CI $[0.028,0.382])$. Thus, hypothesis 1 and 2 were supported. Additionally, the interaction between perspective taking and OBSE proved to have a significantly positive effect on creativity $(\beta=0.230, p<0.05$, 95\% CI $[0.052,0.408])$. Hypothesis 4 was supported. Moreover, the index of the moderated mediation effect was 0.068 , the CI $(0.017,0.145)$ does not include zero, which suggests that employees' OBSE moderates the indirect effect of help-giving during creative problem solving and creativity (through perspective taking). Thus, hypothesis 5 was supported.

The results for hypothesis 3 and 5 are reported in Table 5. Results from the bootstrapped data showed that at 1 standard deviation above the mean on our moderator variable (OBSE), the conditional indirect effect was significant $(\beta=0.111,95 \%$ CI $[0.039,0.212])$. In contrast, as 1 standard deviation below the mean, the conditional indirect effect was small $(\beta=0.010)$, and the $95 \%$ CI does contain zero $[-0.049,0.072])$.

Figure 2 presents the moderating effects between variables.

\section{GENERAL DISCUSSION}

Drawing upon the model of perspective taking, we investigated the link between help-giving during creative problem solving process and creativity. In particular, we found that perspective taking mediated the relationship between these two, while employees' OBSE moderated the link between perspective taking and creativity. Furthermore, employees' OBSE affected the strength of the link between help-giving behavior and creativity via the indirect effect of perspective taking.

\section{Theoretical Implication}

We contribute to the creativity literature by unveiling the behavioral mechanisms that fuel creativity. As previous studies usually focus on the cognitive, affective and motivational predictors of creativity, few have examined individuals' behaviors. Recent work by Mueller and Kamdar's (2011) suggests that help-seeking behavior could also facilitate creativity. The present study manifests that help-seeking is not the only interpersonal process that could contribute to creativity, help-giving can also be conducive to creativity via the indirect effect of perspective taking, especially during the creative problem solving process.

TABLE 2 | Reliability and discriminant validity.

\begin{tabular}{lccc}
\hline Variable & $\begin{array}{c}\text { Cronbach's } \\
\text { alpha }\end{array}$ & $\begin{array}{c}\text { AVE (average } \\
\text { variance } \\
\text { extracted) }\end{array}$ & $\begin{array}{c}\text { Composite } \\
\text { reliability }\end{array}$ \\
\hline Help-giving behavior & 0.923 & 0.675 & 0.925 \\
Perspective taking & 0.946 & 0.814 & 0.946 \\
OBSE & 0.911 & 0.528 & 0.913 \\
Creativity & 0.973 & 0.738 & 0.973 \\
\hline \multicolumn{4}{c}{ Shared variance (square of correlation estimate) } \\
\cline { 2 - 4 } & Help-giving & Perspective & OBSE \\
taking & \\
\hline Help-giving behavior & 1 & & \\
Perspective taking & 0.095 & 1 & 1 \\
OBSE & 0.085 & 0.263 & 0.014 \\
Creativity & 0 & 0.027 &
\end{tabular}


Meanwhile, in the same work, Mueller and Kamdar (2011) also found that help-giving behaviors initiated by previous help-seeking behaviors negatively relates to creativity. In their work, helping giving behaviors are viewed as reciprocation costs of help-seeking, which further leads to performance costs, mainly by diminishing their amount of time and energy that could be devoted to fulfill their own work and by enhancing their problem representation. To explain the difference, firstly, taken into consideration of the reciprocity of help-giving and help-seeking, the diminished amount of time and energy could be replenished by the reciprocal help-seeking behaviors; secondly, the enhanced problem presentation mainly comes from the notion that individuals who seek help from others acknowledge inferiority to other people and might be viewed as less competent than the help-givers in the given domain (Lee, 2002). However, according to Hargadon and Bechky (2006), seeking help from others could also be perceived as a necessary means to bring organization's knowledge to bear during the creative problem solving process and several organizations have set up some regulations to reinforce the help-seeking behaviors. Accordingly, giving help would be more likely viewed as regular instead of the help-givers be more competent and superior to the help-seekers. Thus, there could also be a positive link between help-giving behaviors and creativity. The present study testified that employees' help-giving behavior during creative problem solving process could also contribute to individuals' creativity via the indirect effect of perspective taking. In doing so, this might offer an explanation why the causal relationship between help-giving behavior and creativity turns out to be uncorrelated, the possible positive and negative effect could neutralize and offset each other 's influence.

Besides, based upon the model of perspective taking, we find that individuals' perspective taking behavior could mediate the link between help-giving behavior and their creativity, which add to the literature of discussion on the mixed results of help-giving behaviors. Besides, in doing so, we also enriched the model of perspective taking. For one thing, both the model of perspective taking and a wide array of research concerning the link between perspective taking and helping behaviors all propose that individuals' perspective taking behaviors could predict their cooperative contextual behaviors, like helping behaviors (Oswald, 1996; Vaish et al., 2009). Our study suggested that this could also be the other way around, that is, help-giving behaviors could

TABLE 3 | Means, standard deviations (SD), and correlations ${ }^{a}$

\begin{tabular}{|c|c|c|c|c|c|c|c|c|c|}
\hline Variable & Mean & $S D$ & 1 & 2 & 3 & 4 & 5 & 6 & 7 \\
\hline (1) Gender & 1.543 & 0.499 & 1 & & & & & & \\
\hline (2) Age & 31.933 & 7.548 & $-0.138^{*}$ & 1 & & & & & \\
\hline (3) Education & 2.671 & 0.704 & $-0.135^{*}$ & 0.047 & 1 & & & & \\
\hline (4) Org. Tenure & 7.154 & 7.059 & -0.079 & $0.788^{* *}$ & -0.007 & 1 & & & \\
\hline (5) Help-giving behavior & 5.271 & 0.745 & -0.007 & -0.102 & 0.063 & $-0.197^{* *}$ & - & & \\
\hline (6) Perspective taking & 5.715 & 0.571 & -0.102 & -0.002 & 0.004 & 0.012 & $0.309 * *$ & - & \\
\hline (7) OBSE & 4.734 & 0.686 & -0.078 & -0.051 & $0.128^{*}$ & -0.056 & $0.291^{* *}$ & $0.513^{* *}$ & - \\
\hline (8) Creativity & 5.184 & 0.742 & -0.125 & $0.173^{* *}$ & 0.082 & $0.213^{* *}$ & 0.017 & $0.163^{* *}$ & $0.119^{*}$ \\
\hline
\end{tabular}

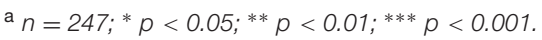

TABLE 4 | Bootstrap confidence intervals for the hypothesized moderated mediation effects.

\begin{tabular}{|c|c|c|c|c|c|c|}
\hline \multirow[t]{2}{*}{ Variable } & \multicolumn{3}{|c|}{ Perspective taking } & \multicolumn{3}{|c|}{ Creativity } \\
\hline & Coefficient & $S E$ & $95 \% \mathrm{Cl}$ & Coefficient & $S E$ & $95 \% \mathrm{Cl}$ \\
\hline \multicolumn{7}{|l|}{ Control variables } \\
\hline Company & -0.024 & 0.039 & $-0.100,0.053$ & $-0.348^{* * *}$ & 0.046 & $-0.439,-0.256$ \\
\hline Gender & -0.120 & 0.077 & $-0.273,0.032$ & -0.016 & 0.093 & $-0.199,0.166$ \\
\hline Age & -0.007 & 0.009 & $-0.024,0.010$ & 0.009 & 0.010 & $-0.012,0.029$ \\
\hline Education & -0.039 & 0.059 & $-0.155,0.078$ & -0.134 & 0.071 & $-0.274,0.007$ \\
\hline Org. Tenure & 0.010 & 0.009 & $-0.009,0.028$ & -0.010 & 0.011 & $-0.032,0.012$ \\
\hline \multicolumn{7}{|l|}{ predictor } \\
\hline Help-giving behavior (T1) & $0.295^{* * *}$ & 0.051 & $0.193,0.396$ & 0.011 & 0.066 & $-0.119,0.142$ \\
\hline Perspective Taking (T2) & & & & $0.205^{*}$ & 0.090 & $0.028,0.382$ \\
\hline OBSE(T2) & & & & -0.001 & 0.075 & $-0.148,0.147$ \\
\hline Interactions: Perspective Taking $\times$ OBSE & & & & $0.230^{*}$ & 0.090 & $0.052,0.408$ \\
\hline Constant & $-1.050^{*}$ & 0.413 & $-1.864,-0.236$ & $6.062^{* * *}$ & 0.505 & $5.068,7.056$ \\
\hline$R^{2}$ & \multicolumn{3}{|c|}{$R^{2}=0.132$} & \multicolumn{3}{|c|}{$R^{2}=0.278$} \\
\hline $\boldsymbol{F}$ & \multicolumn{3}{|c|}{$F(6,238)=6.032 p<0.001$} & \multicolumn{3}{|c|}{$F(9,235)=10.038 p<0.001$} \\
\hline
\end{tabular}

${ }^{*} p<0.05 ;{ }^{* *} p<0.01 ;{ }^{* * *} p<0.001$. 
TABLE 5 | Moderated mediated results for perspective taking across levels of organization-based self-esteem (OBSE)* .

\begin{tabular}{|c|c|c|c|c|}
\hline \multirow[b]{2}{*}{ Moderator = OBSE } & \multicolumn{4}{|c|}{ Perspective taking } \\
\hline & Conditional indirect effect & SE & 95\% BootLLCI & $95 \%$ BootULCI \\
\hline Low (-1 SD) & 0.010 & 0.030 & -0.049 & 0.072 \\
\hline \multirow[t]{2}{*}{ High (+1 SD) } & 0.111 & 0.043 & 0.039 & 0.212 \\
\hline & Bootstrapping effect & SE & \multicolumn{2}{|c|}{ 95\% Cl (LL,UL) } \\
\hline Moderated mediation effect & 0.068 & 0.032 & \multicolumn{2}{|c|}{$0.017,0.145$} \\
\hline
\end{tabular}

*Bootstrap 5,000.

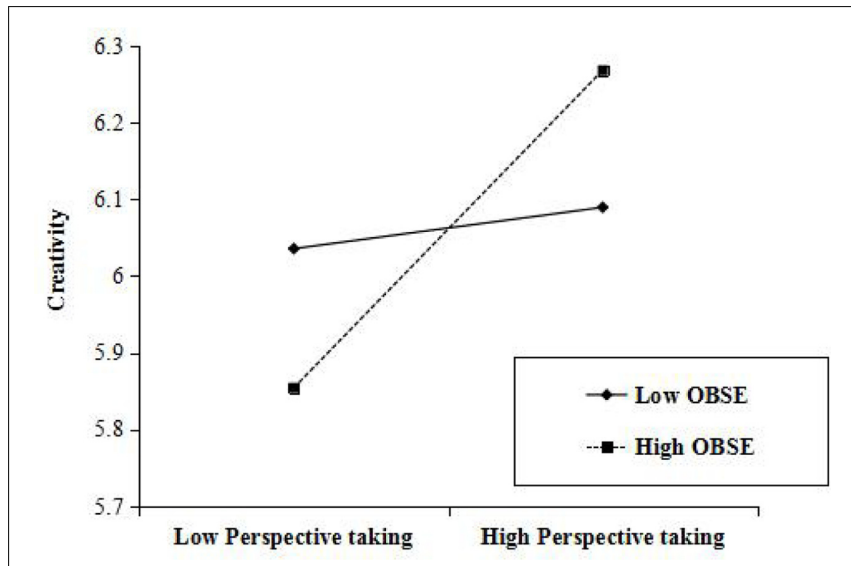

FIGURE 2 | Interaction between employee's perspective taking and OBSE predicting employee's creativity.

also predict individuals' perspective taking, which provides a new perspective to view the perspective taking model. For another, the model of perspective taking maintains that perspective taking behaviors could promote cooperative contextual behaviors as it enhances interpersonal facilitation. Our study suggested that under certain circumstance, individuals' perspective taking behavior could also facilitate job performance like creativity, which indicates a virtuous circle that during the creative process, help-giving behaviors among coworkers could further promote focal employees' creative performance.

We also contribute to the OCB literature by suggesting that help-giving could be beneficial to individual creativity. Recent days, there exists two streams of literature addressing conflicting viewpoints about help-giving behaviors. One is the enrichment-based perspective, which suggests that help-giving behaviors positively relate to a number of individual- and organization-level outcomes, such as positive affect (Koopman et al., 2016), task performance (Allen and Rush, 1998; Hoffman et al., 2007), promotion (Hui et al., 2000), decreased unit-level turnover (Podsakoff et al., 2009), and better wellbeing (Lam et al., 2016). The other is the emerging depletionbased perspective, which indicates that help-giving behaviors positively relate to citizenship fatigue, role overload, job stress, work-family conflict, and decreased task performance. This study contributes to the enrichment-based perspective by showing that mediated by perspective taking, employees' help-giving behavior could also positively contribute to their creativity.

Besides, we also add to the OBSE literature. As research suggests that self-esteem plays a vital part in predicting individuals' motivation, work-related attitudes and behaviors (Pierce et al., 1989; Pierce and Gardner, 2004; Lee and Peccei, 2007), previous research concerning the link between OBSE and creativity usually focuses on its direct effect, that is, how work characteristics and contextual factors like leadership could affect individuals' creativity via the mechanism of OBSE (c.f., CohenMeitar et al., 2009; Zhang et al., 2015). The present study finds out that as an individual difference, OBSE could also be the boundary condition that moderates the link between perspective taking and creativity. Moreover, about the moderating effect of OBSE, align with the behavioral plasticity theory (Brockner, 1983, 1988), most of the work supported the notion that individuals with low self-esteem are more susceptible and reactive to external influence than individuals with high self-esteem (Pierce et al., 1993; Jex and Elacqua, 1999; Brutus et al., 2000; Hui and Lee, 2000). The present study suggests that this should be divided into two, for the negative external cues, individuals with low self-esteem would be more responsive than individuals with high self-esteem; for positive external cues, individuals with high self-esteem would be more responsive than individuals with low self-esteem (see also, Stark et al., 2000). Thus, we enrich the understanding of research on OBSE.

\section{Managerial Implications}

Firstly, our study suggested that a team-based work context is productive when help-giving behaviors during the creative problem solving process could elicit employees' perspective taking; secondly, we re-evaluate the value of help-giving, since the depletion-based perspective are becoming more and more pervasive, we are afraid that there will be less and less helpgiving behaviors in workplace, which we could also tell from the emerging and intensified knowledge hiding, selfishness in work groups (Margolis, 1984; Černe et al., 2014). Thus, we hope this study might offer some enlightenment and evidence to reassure their concern of giving a hand to others during work. Moreover, organizations should recruit individuals with high OBSE and also cultivate their employees' OBSE during work in order to enhance their motivation to conduct creative endeavors. 


\section{Limitations and Directions for Future Research}

In addition, the present study is not without limitations. Firstly, we did not control the help-seeking behavior, given the importance of this behavior in the discussion of the link between help-giving and creativity, future studies should control it; secondly, we collected data from a field survey, which cannot conclusively rule out alternative directionality. Nonetheless, our research design of collecting data in three-pointed phases and multi-source can increase confidence in the temporal directionality and the generalization of our results. Besides, field design has its own disadvantages, for example, our study just implied variables that we are interested, we can't rule out other alternatives, so we also call for experiments to replicate our results. Also, we adopt a subject way to measure creativity (i.e., supervisors' ratings), which could be biased, for example, by the halo effect. Although it is common in the organizational creativity literature to use supervisors as a measure of creativity, it is of significance for further research to use both supervisor ratings and objective measures to reflect employees' actual creative performance. Moreover, as we collected our data in China, there might be some problems with the generalization of our research findings. However, we collected our research samples in two of the most open cities in China, and most of the business both of the two logistics enterprises are dealing with is foreign trade. More importantly, both of the two logistics enterprises are international companies, within which their

\section{REFERENCES}

Allen, T. D., and Rush, M. C. (1998). The effects of organizational citizenship behavior on performance judgments: a field study and a laboratory experiment. J. Appl. Psychol. 83, 247-260. doi: 10.1037/0021-9010.83. 2.247

Amabile, T. M. (1983). The social psychology of creativity: a componential conceptualization. J. Pers. Soc. Psychol. 45, 357-376. doi: 10.1037/0022-3514. 45.2.357

Amabile, T. M. (1988). "A model of creativity and innovation in organizations," in Research in Organizational Behavior, Vol. 10, eds B. M. Staw and L. Cummings (Greenwich, CT: JAI Press), 123-167.

Amabile, T. M. (1996). Creativity in Context: Update to "the Social Psychology of Creativity". Boulder, CO: Westview press.

Barnes, C. M., Hollenbeck, J. R., Wagner, D. T., DeRue, D. S., Nahrgang, J. D., and Schwind, K. M. (2008). Harmful help: the costs of backing-up behavior in teams. J. Appl. Psychol. 93:529. doi: 10.1037/0021-9010.93.3.529

Baron, R. M., and Kenny, D. A. (1986). The moderator-mediator variable distinction in social psychological research: conceptual, strategic, and statistical considerations. J. Pers. Soc. Psychol. 51, 1173-1182. doi: 10.1037/0022-3514.51. 6.1173

Batson, C. D. (1997). Self-other merging and the empathy-altruism hypothesis: reply to Neuberg et al. (1997). J. Pers. Soc. Psychol. 73, 517-522. doi: 10.1037/ 0022-3514.73.3.517

Batson, C. D., and Powell, A. A. (2003). "Altruism and prosocial behavior," in Handbook of Psychology: Personality and Social Psychology, Vol. 5, eds T. Millon and J. Lerner (New York, NY: John Wiley \& Sons), 463-484. doi: 10.1002/ 0471264385.wei0519

Batson, C. D., Sympson, S. C., Hindman, J. L., Decruz, P., Todd, R. M., Weeks, J. L., et al. (1996). "I've been there, too": effect on empathy of prior experience with a need. Pers. Soc. Psychol. Bull. 22, 474-482. doi: 10.1177/014616729622 5005 employees flow between the international branches. Thus, we can conclude that our research findings could be generalized to other population. Nonetheless, future studies should still replicate our research using different samples to validate our findings. Lastly, we just control the demographics of employees and the company membership, future research could explore other variables which influence the relationship.

\section{AUTHOR CONTRIBUTIONS}

SiL and ShL contribute to the paper in different ways. And we really appreciate the work of the associate editor and the three reviewers.

\section{FUNDING}

This research is funded by the National Natural Science Foundation of China (Grant No. 71572066).

\section{SUPPLEMENTARY MATERIAL}

The Supplementary Material for this article can be found online at: http://journal.frontiersin.org/article/10.3389/fpsyg. 2017.01030/full\#supplementary-material

Bergeron, D. M. (2007). The potential paradox of organizational citizenship behavior: good citizens at what cost? Acad. Manag. Rev. 32, 1078-1095. doi: 10.5465/amr.2007.26585791

Bolino, M. C., Hsiung, H. H., Harvey, J., and LePine, J. A. (2015). “Well, I'm tired of tryin'?" Organizational citizenship behavior and citizenship fatigue. J. Appl. Psychol. 100, 56-74. doi: 10.1037/a0037583

Bolino, M. C., and Turnley, W. H. (2005). The personal costs of citizenship behavior: the relationship between individual initiative and role overload, job stress, and work-family conflict. J. Appl. Psychol. 90, 740-748. doi: 10.1037/ 0021-9010.90.4.740

Brislin, R. W. (1986). "The wording of translation of research instruments," in Field Methods in Cross-Cultural Research, eds W. J. Lonner and J. W. Berry (Beverly Hills, CA: Sage), 137-164.

Brockner, J. (1983). Low self-esteem and behavioral plasticity: some implications. Rev. Pers. Soc. Psychol. 4, 237-271.

Brockner, J. (1988). Self-esteem at Work: Research, Theory, and Practice. Lexington, MA: Lexington Books.

Brutus, S., Ruderman, M. N., Ohlott, P. J., and Mccauley, C. D. (2000). Developing from job experiences: the role of organization-based self-esteem. Hum. Resour. Dev. Q. 11, 367-380. doi: 10.1002/1532-1096(200024)11:4<367::AID-HRDQ4> 3.0.CO;2-6

Černe, M., Nerstad, C. G., Dysvik, A., and Škerlavaj, M. (2014). What goes around comes around: knowledge hiding, perceived motivational climate, and creativity. Acad. Manag. J. 57, 172-192. doi: 10.5465/amj.2012.0122

Chen, Z. X., and Aryee, S. (2007). Delegation and employee work outcomes: an examination of the cultural context of mediating processes in China. Acad. Manag. J. 50, 226-238. doi: 10.5465/AMJ.2007.24162389

Cohen, S. G., and Bailey, D. E. (1997). What makes teams work: group effectiveness research from the shop floor to the executive suite. J. Manag. 23, 239-290. doi: $10.1177 / 014920639702300303$

Cohen-Meitar, R., Carmeli, A., and Waldman, D. A. (2009). Linking meaningfulness in the workplace to employee creativity: the intervening 
role of organizational identification and positive psychological experiences. Creat. Res. J. 21, 361-375. doi: 10.1080/10400410902969910

Davis, L. E., and Wacker, G. J. (1987). "Job design," in Handbook of Human Factors, ed. G. Salvendy (New York, NY: John Wiley), 431-445.

Davis, M. H., Conklin, L., Smith, A., and Luce, C. (1996). Effect of perspective taking on the cognitive representation of persons: a merging of self and other. J. Pers. Soc. Psychol. 70, 713-726. doi: 10.1037/0022-3514.70.4.713

De Stobbeleir, K. E., Ashford, S. J., and Buyens, D. (2011). Self-regulation of creativity at work: the role of feedback-seeking behavior in creative performance. Acad. Manag. J. 54, 811-831. doi: 10.5465/AMJ.2011.6487 0144

Duan, C., and Hill, C. E. (1996). The current state of empathy research. J. Couns. Psychol. 43, 261-274. doi: 10.1037/0022-0167.43.3.261

Durkheim, E. (2014). The Division of Labor in Society. New York, NY: Simon and Schuster.

Edwards, J. R., and Lambert, L. S. (2007). Methods for integrating moderation and mediation: a general analytical framework using moderated path analysis. Psychol. Methods 12, 1-22. doi: 10.1037/1082-989X.12.1.1

Fleming, L. (2001). Recombinant uncertainty in technological search. Manag. Sci. 47, 117-132. doi: $10.1287 /$ mnsc.47.1.117.10671

Galinsky, A. D., Maddux, W. W., Gilin, D., and White, J. B. (2008). Why it pays to get inside the head of your opponent the differential effects of perspective taking and empathy in negotiations. Psychol. Sci. 19, 378-384. doi: 10.1111/j. 1467-9280.2008.02096.x

George, J. M. (2007). 9 creativity in organizations. Acad. Manag. Ann. 1, 439-477. doi: $10.1080 / 078559814$

Guilford, J. P. (1967). Creativity: yesterday, today and tomorrow. J. Creat. Behav. 1, 3-14. doi: 10.1002/j.2162-6057.1967.tb00002.x

Hair, J. F., Anderson, R. E., Babin, B. J., and Black, W. C. (2010). Multivariate Data Analysis: A Global Perspective, Vol. 7. Upper Saddle River, NJ: Pearson.

Hargadon, A. B., and Bechky, B. A. (2006). When collections of creatives become creative collectives: a field study of problem solving at work. Organ. Sci. 17, 484-500. doi: $10.1287 /$ orsc. 1060.0200

Hayes, A. F. (2013). Introduction to Mediation, Moderation, and Conditional Process Analysis: A Regression-based Approach. New York, NY: Guilford Press.

Hobfoll, S. E. (1989). Conservation of resources: a new attempt at conceptualizing stress. Am. Psychol. 44, 513-524. doi: 10.1037/0003-066X.44. 3.513

Hoffman, B. J., Blair, C. A., Meriac, J. P., and Woehr, D. J. (2007). Expanding the criterion domain? A quantitative review of the OCB literature. J. Appl. Psychol. 92, 555-566. doi: 10.1037/0021-9010.92.2.555

Hui, C., Lam, S. S., and Law, K. K. (2000). Instrumental values of organizational citizenship behavior for promotion: a field quasi-experiment. J. Appl. Psychol. 85, 822-828. doi: 10.1037/0021-9010.85.5.822

Hui, C., and Lee, C. (2000). Moderating effects of organization-based self-esteem on organizational uncertainty: employee response relationships. J. Manag. 26, 215-232. doi: 10.1177/014920630002600203

Jex, S. M., and Elacqua, T. C. (1999). Self-esteem as a moderator: a comparison of global and organization-based measures. J. Occup. Organ. Psychol. 72, 71-81. doi: 10.1016/j.jad.2016.08.049

Katz, D., and Kahn, R. L. (1978). The Social Psychology of Organizations, Vol. 2. New York, NY: Wiley.

Kesen, M. (2016). Linking organizational identification with individual creativity: organizational citizenship behavior as a mediator. J. Yaşar Univ. 11, 56-66. doi: $10.19168 /$ jyu. 47683

Koopman, J., Lanaj, K., and Scott, B. A. (2016). Integrating the bright and dark sides of OCB: a daily investigation of the benefits and costs of helping others. Acad. Manag. J. 59, 414-435. doi: 10.5465/amj.2014.0262

Korman, A. K. (1970). Toward an hypothesis of work behavior. J. Appl. Psychol. 54, 31-41. doi: 10.1037/h0028656

Korman, A. K. (1976). Hypothesis of work behavior revisited and an extension. Acad. Manag. Rev. 1, 50-63. doi: 10.5465/AMR.1976.4408762

Lam, C. F., Wan, W. H., and Roussin, C. J. (2016). Going the extra mile and feeling energized: an enrichment perspective of organizational citizenship behaviors. J. Appl. Psychol. 101, 379-391. doi: 10.1037/apl0000071

Lee, F. (2002). The social costs of seeking help. J. Appl. Behav. Sci. 38, 17-35. doi: $10.1177 / 0021886302381002$
Lee, J., and Peccei, R. (2007). Perceived organizational support and affective commitment: the mediating role of organization-based self-esteem in the context of job insecurity. J. Organ. Behav. 28, 661-685. doi: 10.1002/ job.431

Maner, J. K., Luce, C. L., Neuberg, S. L., Cialdini, R. B., Brown, S., and Sagarin, B. J. (2002). The effects of perspective taking on motivations for helping: still no evidence for altruism. Pers. Soc. Psychol. Bull. 28, 1601-1610. doi: 10.1177/ 014616702237586

Margolis, H. (1984). Selfishness, Altruism, and Rationality. Chicago, IL: University of Chicago Press.

Metcalfe, J., and Wiebe, D. (1987). Intuition in insight and noninsight problem solving. Mem. Cogn. 15, 238-246. doi: 10.3758/BF03197722

Mohrman, S. A., Gibson, C. B., and Mohrman, A. M. (2001). Doing research that is useful to practice a model and empirical exploration. Acad. Manag. J. 44, 357-375. doi: 10.2307/3069461

Mueller, J. S., and Kamdar, D. (2011). Why seeking help from teammates is a blessing and a curse: a theory of help seeking and individual creativity in team contexts. J. Appl. Psychol. 96, 263-276. doi: 10.1037/a00 21574

Mumford, M. D. (2003). Where have we been, where are we going? Taking stock in creativity research. Creat. Res. J. 15, 107-120. doi: 10.1080/10400419.2003. 9651403

Mumford, M. D., and Gustafson, S. B. (1988). Creativity syndrome: integration, application, and innovation. Psychol. Bull. 103, 27-43. doi: 10.1037/0033-2909. 103.1.27

Ng, T. W., and Feldman, D. C. (2008). The relationship of age to ten dimensions of job performance. J. Appl. Psychol. 93, 392-423. doi: 10.1037/0021-9010.93. 2.392

Oswald, P. A. (1996). The effects of cognitive and affective perspective taking on empathic concern and altruistic helping. J. Soc. Psychol. 136, 613-623. doi: 10.1080/00224545.1996.9714045

Parker, S. K., and Axtell, C. M. (2001). Seeing another viewpoint: antecedents and outcomes of employee perspective taking. Acad. Manag. J. 44, 1085-1100. doi: $10.2307 / 3069390$

Parker, S. K., Wall, T. D., and Jackson, P. R. (1997). "That's not my job”: developing flexible employee work orientations. Acad. Manag. J. 40, 899-929. doi: 10.2307/ 256952

Perlow, L. A. (1998). Boundary control: the social ordering of work and family time in a high-tech corporation. Adm. Sci. Q. 43, 328-357. doi: 10.2307/2393855

Perlow, L. A. (1999). The time famine: toward a sociology of work time. Adm. Sci. Q. 44, 57-81. doi: 10.2307/2667031

Perry-Smith, J. E., and Shalley, C. E. (2003). The social side of creativity: a static and dynamic social network perspective. Acad. Manag. Rev. 28, 89-106.

Pierce, J. L., and Gardner, D. G. (2004). Self-esteem within the work and organizational context: a review of the organization-based self-esteem literature. J. Manag. 30, 591-622. doi: 10.1016/j.jm.2003.10.001

Pierce, J. L., Gardner, D. G., Cummings, L. L., and Dunham, R. B. (1989). Organization-based self-esteem: construct definition, measurement, and validation. Acad. Manag. J. 32, 622-648. doi: 10.2307/256437

Pierce, J. L., Gardner, D. G., Dunham, R. B., and Cummings, L. L. (1993). Moderation by organization-based self-esteem of role conditionemployee response relationships. Acad. Manag. J. 36, 271-288. doi: 10.2307/ 256523

Podsakoff, N. P., Whiting, S. W., Podsakoff, P. M., and Blume, B. D. (2009). Individual-and organizational-level consequences of organizational citizenship behaviors: a meta-analysis. J. Appl. Psychol. 94, 122-141. doi: 10.1037/a0013079

Shalley, C. E. (1991). Effects of productivity goals, creativity goals, and personal discretion on individual creativity. J. Appl. Psychol. 76, 179-185. doi: 10.1037/ 0021-9010.76.2.179

Shalley, C. E., Zhou, J., and Oldham, G. R. (2004). The effects of personal and contextual characteristics on creativity: where should we go from here? J. Manag. 30, 933-958. doi: 10.1016/j.jm.2004.06.007

Shin, S. J., and Zhou, J. (2003). Transformational leadership, conservation, and creativity: evidence from Korea. Acad. Manag. J. 46, 703-714. doi: 10.2307/ 30040662

Simonton, D. K. (1984). Artistic creativity and interpersonal relationships across and within generations. J. Pers. Soc. Psychol. 46, 1273-1286. doi: 10.1037/00223514.46.6.1273 
Stark, E., Thomas, L. T., and Poppler, P. (2000). Psychological disposition and job satisfaction under varying conditions of organizational change: relevance and meaning from survivors and walking wounded. Paper Presented at the Annual meeting of the Western Academy of Management, Kona, HI.

Stevens, M. J., and Campion, M. A. (1994). The knowledge, skill, and ability requirements for teamwork: implications for human resource management. J. Manag. 20, 503-530. doi: 10.1177/014920639402000210

Tepper, B. J., Lockhart, D., and Hoobler, J. (2001). Justice, citizenship, and role definition effects. J. Appl. Psychol. 86, 789-796. doi: 10.1037/0021-9010.86. 4.789

Tierney, P., and Farmer, S. M. (2002). Creative self-efficacy: its potential antecedents and relationship to creative performance. Acad. Manag. J. 45, 1137-1148. doi: 10.2307/3069429

Underwood, B., and Moore, B. (1982). Perspective-taking and altruism. Psychol. Bull. 91, 143-173. doi: 10.1037/0033-2909.91.1.143

Vaish, A., Carpenter, M., and Tomasello, M. (2009). Sympathy through affective perspective taking and its relation to prosocial behavior in toddlers. Dev. Psychol. 45, 534-543. doi: 10.1037/a0014322

Van Scotter, J. R., and Motowidlo, S. J. (1996). Interpersonal facilitation and job dedication as separate facets of contextual performance. J. Appl. Psychol. 81, 525-531. doi: 10.1037/0021-9010.81.5.525
Zhang, S., Ke, X., and Wang, X. (2015). "Empowering leadership and creativity: the influence of access to resources/information, and OBSE," in Proceedings of the Academy of Management (Briarcliff Manor, NY: Academy of Management), 16035. doi: 10.5465/ambpp.2015.16035abstract

Zhou, J., and George, J. M. (2001). When job dissatisfaction leads to creativity: encouraging the expression of voice. Acad. Manag. J. 44, 682-696. doi: 10.2307/ 3069410

Zhou, J., and Hoever, I. J. (2014). Research on workplace creativity: a review and redirection. Annu. Rev. Organ. Psychol. Organ. Behav. 1, 333-359. doi: 10.1146/ annurev-orgpsych-031413-091226

Conflict of Interest Statement: The authors declare that the research was conducted in the absence of any commercial or financial relationships that could be construed as a potential conflict of interest.

Copyright (c) $2017 \mathrm{Li}$ and Liao. This is an open-access article distributed under the terms of the Creative Commons Attribution License (CC BY). The use, distribution or reproduction in other forums is permitted, provided the original author(s) or licensor are credited and that the original publication in this journal is cited, in accordance with accepted academic practice. No use, distribution or reproduction is permitted which does not comply with these terms. 